the question with an existing scale and not a semistructured interview. ${ }^{45}$ Such a subjective question requires further rigorous evaluation before we advocate its widespread application to screen for depression in patients with advanced cancer.

Contributors: ML-W and MD designed and developed the study ML-W, FT, and IB carried out the study. ML-W, MD, and FT analysed the data. ML-W and MD drafted the paper; all authors revised and approved the final version. ML-W and MD are guarantors.

Funding: A PPP grant.

Competing interests: None declared.
Ethical approval: Leicestershire Health Authority.

Hotopf M, Chidgey J, Addington-Hall J, Lan Ly K. Depression in advanced disease: a system

2 Lloyd-Williams M, Friedman T, Rudd N. A survey of antidepressant prescribing in the terminally ill. Palliat Med 1999;13:243-8.

Chochinov H, Wilson K, Enns M, Lander S. “Are you depressed?” Screening for depression in the terminally ill. Am J Psychiatry 1997;154:674-6.

4 Mahoney J, Drinka TJ, Abler R, Gunter-Hunt G, Matthews C, Gravenstein $\mathrm{S}$, et al. Screening for depression: single question versus GDS. J Am Geriatr Soc 1994;42:1006-8.

5 Watkins C, Daniels L, Jack C, Dickinson H, van den Broek M. Accuracy of a single question in screening for depression in a cohort of patients after stroke: comparative study. BMJ 2001;323:1159.

(Accepted 1 May 2003) advanced disease: a systematic review. Part 1: Prevalence and case finding.

\section{Risk of suicide in twins: 51 year follow up study}

Cecilia Tomassini, Knud Juel, Niels V Holm, Axel Skytthe, Kaare Christensen
Strong family ties and commitments are known to be important in the prevention of suicide. Having parents alive and together, being married, and having young children are negatively correlated with risk of suicide. ${ }^{1-3}$ The presence of siblings, however, has rarely been looked at in studies of suicide or attempted suicide. A Danish register study found no protective effect associated with having siblings, ${ }^{1}$ but neither the age nor the sex of siblings was considered. Twins represent a unique sibling relationship. They not only share the same family and social environment at least for the first part of their lives, but they also show a higher level of closeness both in terms of the number of years spent together before leaving the parental home and in the frequency of contacts afterwards. We investigated whether the suicide rate in twins was different to that in the general population.

\section{Participants, methods, and results}

Through the population based Danish twin registry we identified same sex twins born from 1870 to 1930 and established date and cause of death from 1943 to 1993 through the Danish registry of causes of death (this register linkage has previously been described in more detail $\left.^{4}\right)$. We included 21653 individual twins alive on 1 January 1943, 13318 (62\%) of whom died during the follow up.

From 1951 we coded the cause of death according to the ICD-6, ICD-7, and ICD-8 (international classification of diseases, sixth, seventh, and eighth editions). For deaths from before 1951 we used the coding system of the Danish registry of causes of death. Here we report on the deaths coded as suicide (1943-50: Danish registry codes 900-930; 1951-68: ICD-6 and 7 codes 970-979; 1969-93: ICD-8 codes 950-969). We calculated the expected number suicides in the twin population by multiplying the observed person years with suicide rates for Denmark stratified for sex, one year age group, and five year calendar period (source: the Danish registry of causes of death). Standardised suicide rates were calculated as the observed number of suicides divided by the expected number of suicides.
As previously reported ${ }^{4}$ the twin cohorts had a mortality pattern similar to that in the general population (standardised mortality 0.95 for men and 0.98 for women). However, twins had a substantially lower suicide rate compared with the general population, with 211 observed suicides versus 292.8 expected, corresponding to a standardised suicide rate of 0.74 for men $(95 \%$ confidence interval 0.62 to 0.88$)$ and 0.69 for women ( 0.55 to 0.86 ) (table). The suicide risk for twins was consistently lower for both men and women in all six 10 year birth cohorts. We also considered the risk of suicide stratified by cohorts and follow up time (1-25 years and $\geq 25$ years). All strata consistently showed a reduced suicide risk for twins, indicating no age or cohort differences. Furthermore, the suicide rate was of similar size in monozygotic and dizygotic twins.

Suicide rate among Danish twins born 1870-1930 and followed up to 1 January 1943-31 December 1993*

\begin{tabular}{|c|c|c|c|c|}
\hline \multirow[b]{2}{*}{ Birth cohort } & \multirow{2}{*}{$\begin{array}{c}\text { Alive on } 1 \text { January } \\
1943\end{array}$} & \multicolumn{2}{|c|}{ Suicides } & \multirow{2}{*}{$\begin{array}{l}\text { Standardised suicide } \\
\text { rates }(95 \% \mathrm{Cl}) \dagger\end{array}$} \\
\hline & & Observed & Expected & \\
\hline \multicolumn{5}{|l|}{$1870-9$} \\
\hline Men & 663 & 0 & 4.4 & 0 \\
\hline Women & 790 & 2 & 2.4 & 0.84 (0.10 to 3.03$)$ \\
\hline \multicolumn{5}{|l|}{ 1880-9 } \\
\hline Men & 1021 & 9 & 10.1 & 0.89 (0.41 to 1.69$)$ \\
\hline Women & 1159 & 2 & 6.4 & 0.31 (0.04 to 1.13 ) \\
\hline \multicolumn{5}{|l|}{$1890-9$} \\
\hline Men & 1390 & 15 & 20.4 & 0.73 (0.41 to 1.21$)$ \\
\hline Women & 1483 & 4 & 12.1 & 0.33 (0.09 to 0.84$)$ \\
\hline \multicolumn{5}{|l|}{$1900-9$} \\
\hline Men & 1888 & 25 & 34.7 & 0.72 (0.47 to 1.06$)$ \\
\hline Women & 2048 & 16 & 23.5 & 0.68 (0.39 to 1.10$)$ \\
\hline \multicolumn{5}{|l|}{ 1910-9 } \\
\hline Men & 2301 & 42 & 47.0 & 0.89 (0.64 to 1.21$)$ \\
\hline Women & 2736 & 26 & 35.9 & $0.72(0.47$ to 1.06$)$ \\
\hline \multicolumn{5}{|l|}{ 1920-30 } \\
\hline Men & 2933 & 37 & 56.3 & 0.66 (0.46 to 0.91$)$ \\
\hline Women & 3241 & 33 & 39.4 & 0.84 (0.58 to 1.18 ) \\
\hline \multicolumn{5}{|l|}{ All } \\
\hline Men & 10196 & 128 & 173.0 & 0.74 (0.62 to 0.88 ) \\
\hline Women & 11457 & 83 & 119.8 & 0.69 (0.55 to 0.86$)$ \\
\hline
\end{tabular}

*For 1951 and 1952 suicides were not coded separately and therefore both observed and expected suicides in these two years are omitted from calculations.

tBased on Poisson distribution.

Centre for

Population Studies London School of Tropical Medicine, London

WC1 E7HT

Cecilia Tomassini research fellow

continued over

BMJ 2003;327:373-4 
National Institute of

Public Health,

DK-2100

Copenhagen,

Denmark

Knud Juel

senior scientist

Danish Twin

Registry, Institute of

Public Health,

University of

Southern Denmark,

Sdr Boulevard 23A

DK-5000 Odense,

Denmark

Niels V Holm

consultant

Axel Skytthe

senior scientist

Kaare Christensen

professor

Correspondence to:

K Christensen

kchristensen@

health.sdu.dk

\section{Comment}

Twins have a reduced risk of suicide, which supports the hypothesis that strong family ties reduce the risk for suicidal behaviour. This finding was consistent across cohorts, sex, and zygosity. As we used population based register data there was little room for selection bias. The strongest risk factor for suicide is mental illness, ${ }^{2}$ but other Danish register studies have found mental illness to be slightly more common among twins than among singletons. ${ }^{5}$ This should lead to a higher proportion of twins committing suicide compared with the general population, but our findings show exactly the opposite, further underscoring the importance of strong family ties.

Contributors: CT and KC proposed the current use of already existing data on Danish twins' mortality. These data were collected by NVH and AS and analysed by KJ. CT prepared the first draft of the paper. All authors took part in discussions about the design, analyses, and reporting of the study, made individual contributions to the final content of the paper, and approved the final version for publication. $\mathrm{KC}$ is the guarantor.
Funding: The US National Institute on Aging research grant NIA-PO1-AG08761, the Danish Cancer Society (36/79), and the National Cancer Institute (R35 CA 42581). The guarantor accepts full responsibility for the conduct of the study, had access to the data, and controlled the decision to publish.

Competing interests: None declared.

1 Agerbo E, Nordentoft M, Mortensen PB. Familial, psychiatric, and socioeconomic risk factors for suicide in young people: nested case-control study. BMJ 2002;325:74-7.

2 Mortensen PB, Agerbo E, Erikson T, Qin P, Westergaard-Nielsen N. Psychiatric illness and risk factors for suicide in Denmark. Lancet 2000;355:9-12.

3 Qin P, Agerbo E, Westergard-Nielsen N, Eriksson T, Mortensen PB. Gender differences in risk factors for suicide in Denmark. Br J Psychiatry 2000;177:546-50

4 Christensen K, Wienke A, Skytthe A, Holm NV, Vaupel JW, Yashin AI. Cardiovascular mortality in twins and the fetal origins hypothesis. Twin Research 2001;4:344-9.

5 Klaning U, Mortensen PB, Kyvik KO. Increased occurrence of schizophrenia and other psychiatric illnesses among twins. BrJ Psychiatry 1996;168:688-92

(Accepted 6 June 2003)

\section{A memorable exam}

On moving from the primarily English speaking Canadian province of Ontario to predominantly francophone Quebec in the late 1970 s, I had to pass a French language proficiency test in order to receive my medical licence. I was already bilingual (native English and reasonable Hebrew) and had studied French in high school. However, nearly 15 years had passed since I had last said "bonjour" to my teacher, and so I had to go back to night school.

In addition to my formal language studies, I watched cartoons on television, perused the French press, and studied the television news "en français" (after learning the main facts on the English version, which came on earlier). I assiduously studied, practised in front of a mirror, and tortured my poor French speaking patients, who were both enormously kind and helpful.

We "immigrant" physicians had one year to prove our linguistic competency, with an option for another year of study should one fail the initial test. Until receiving a certificate of language proficiency, our medical licences were deemed "temporaire" only. The exam comprised two parts: the first, taken in a language laboratory, involved reading and listening comprehension. Always pretty good at exams, I passed this one with relative ease. But it was the viva which frightened me to death.

Apparently, I belong to one of those rare breeds which finds it easier in the early stages of language acquisition to speak than to understand. (My wife claims I frequently suffer from the same syndrome even in English.) As such, I was afraid that I might not understand something my examiner asked me. But that was not to be the problem.

On the day of my oral exam, I arrived at the headquarters of the "Office de la langue francaise" (what we Anglos called the headquarters of the language cops). The examiner, about 10 years my senior, was polished, polite, and spoke French clearly and precisely. Phew, no problem with comprehension. And as the exam went forward, we seemed to get on famously.

It looked as if things were winding down and that my ordeal was nearing its end. I felt an enormous sense of relief creeping over me. Apparently as an afterthought (was this a trick?), my examiner asked if he could get some medical advice. "Bien sur," I answered. His 10 year old daughter had been diagnosed with infectious mononucleosis a week ago, and he wanted to know if she was in any danger.

Confidently (both medically and linguistically) I hastened to reassure him, explaining that virtually everyone made a complete recovery from this viral illness. That being said, his daughter should be sure to avoid contact sports for the next few weeks to reduce the small but real chance of a traumatic rupture of the... Oh, no. For the life of me (and I felt that my professional life might well depend on it), I could not remember the French word for spleen. I racked my brains: no, "le foie" was the liver, "les reins" were the kidneys, not "poumons," not "coeur." I was "sans eyes, sans mind, sans everything."

Growing desperate, I finally did what I had learnt to do in everyday life in la belle province. I started again and slowly said the whole sentence in French. However, when I got to the bloody organ in question, I just said "splin" in my most Peter Sellers-like French accent. My examiner did not seem to notice, smiled, and thanked me for my reassurance.

He told me that I had passed the exam and complimented me not only on my comprehension but on the quality of my spoken French. He even smiled and said that my accent was not at all bad. The gentleman shook my hand and led me the door of the exam room, ushering me out into the corridor.

How could I have done it? Had he not heard? Did he not care? Could the French word for spleen really be "splin"? Impossible, but what did I care as I was on my way to receiving my certificate?

As I walked down the corridor on the way to the elevator, the examiner called out to me, this time in perfect unaccented English: "Oh, Dr Clarfield."

"Oui?" I turned, fearing the worst.

"By the way," he informed me, "the proper French word for spleen is "la rate."

"Merci beaucoup" was all I could think to say.

A Mark Clarfield professor, Ben Gurion University of the Negev, Beersheva, Israel

markclar@bgumail.bgu.ac.il

We welcome articles up to 600 words on topics such as A memorable patient, A paper that changed my practice, My most unfortunate mistake, or any other piece conveying instruction, pathos, or humour. Please submit the article on http:// submit.bmj.com Permission is needed from the patient or a relative if an identifiable patient is referred to. We also welcome contributions for "Endpieces," consisting of quotations of up to 80 words (but most are considerably shorter) from any source, ancient or modern, which have appealed to the reader. 